\title{
Effect of tangeretin on ovalbumin-provoked allergic respiratory asthma in Swiss albino mice
}

\author{
Liang-mei $\mathrm{Li}^{1 *}$, Wei $\mathrm{Liu}^{2}$ \\ ${ }^{1}$ Department of Respiratory Medicine, Ji'nan Zhangqiu District Hospital of Traditional Chinese Medicine, ${ }^{2}$ Department of \\ Radiological, The First People's Hospital of Jinan, Ji'nan, Shandong 250200, China
}

*For correspondence: Email: liliangmei1203@hotmail.com; Tel/Fax: 0086-0531-83265813

\begin{abstract}
Purpose: To evaluate the effect of tangeretin on ovalbumin (OVA)-induced allergic respiratory asthma in Swiss albino mice.

Methods: Mice were injected intraperitoneally with $50 \mu \mathrm{g}$ OVA dissolved in water and $1 \mathrm{mg}$ of aluminium hydroxide (alum) on the first day, and on day 12. On days 22, 26 and 30, the mice were exposed to $1 \%$ OVA for $30 \mathrm{~min}$. Mice in the asthma control group received saline via the same route. Tangeretin (50 or $100 \mathrm{mg} / \mathrm{kg}$ body weight) was given orally from day 1 to day 30 . On the day of sensitization and challenge, tangeretin (50 or $100 \mathrm{mg} / \mathrm{kg}$ body weight) was injected $30 \mathrm{~min}$ prior to the treatment. Bronchial function, degree of inflammation, broncho-alveolar lavage fluid (BALF), levels of $I L-4, I L-5, I L-13$ and IFN-y in BALF, serum total IgE, OVA-specific IgE, IgG1 and IgG2a, as well as histopathology of lungs were determined.

Results: Tangeretin administration led to significant reduction in airway sensitivity, and significant decreases in leukocyte, macrophage, and eosinophil counts $(p<0.05)$. It also brought about significant decreases in the levels of the pro-inflammatory cytokines (IL-4, IL-5 and IL-13) in both BALF and serum $(p<0.05)$. In addition, tangeretin reversed the OVA-induced histopathological anomalies in the lungs.

Conclusion: These results demonstrate that tangeritin exerts protective effects against OVA-induced allergic respiratory asthma in Swiss albino mice, and that the drug can potentially be developed for the management of allergic asthma.
\end{abstract}

Keywords: Allergic asthma, Inflammation, Cytokines, Ovalbumin, Tangeretin

This is an Open Access article that uses a funding model which does not charge readers or their institutions for access and distributed under the terms of the Creative Commons Attribution License (http://creativecommons.org/licenses/by/4.0) and the Budapest Open Access Initiative (http://www.budapestopenaccessinitiative.org/read), which permit unrestricted use, distribution, and reproduction in any medium, provided the original work is properly credited.

Tropical Journal of Pharmaceutical Research is indexed by Science Citation Index (SciSearch), Scopus, International Pharmaceutical Abstract, Chemical Abstracts, Embase, Index Copernicus, EBSCO, African Index Medicus, JournalSeek, Journal Citation Reports/Science Edition, Directory of Open Access Journals (DOAJ), African Journal Online, Bioline International, Open-J-Gate and Pharmacy Abstracts

\section{INTRODUCTION}

Asthma is a severe, long-lasting inflammatory ailment characterised by reversible respiratory airway congestion. Presently, it affects about 300 million persons globally, and its incidence increases at the rate of $50 \%$ per decade [1]. Respiratory inflammation results in intermittent wheezing, shortness of breath and chest congestion, particularly during the evening period, and in the early hours of the day. These events are normally connected with respiratory

C 2018 The authors. This work is licensed under the Creative Commons Attribution 4.0 International License 
blockage. Allergic respiratory inflammation is thought to be aggravated by changes in the levels of cytokines [2]. Presently, the precise pathway for the development of asthma is uncertain. Despite the use of extant drugs for asthma (mostly $\beta 2$ receptor antagonists), exacerbations of asthmatic symptoms still occur, probably because these agents do not cause alterations in the causative pathological pathways [2].

Several animal models for screening antiasthmatic effects of new pharmacological interventions have been developed. In the present study, allergy-based animal model was used.

Tangeretin is one of the important polymethoxylated flavones abundantly available in citrus fruits. Studies have shown that tangeretin possesses anti-cancer, antioxidant and anti-inflammatory properties [3-5]. Apart from its antioxidant property, tangeretin has been shown to reduce the development of hepatic cancer in vivo as well as in vitro [6].

In the present study which was based on the extensive beneficial properties of tangeretin, the anti-inflammatory and immunomodulatory activities of tangeretin were investigated in a mouse model of allergic asthma. The chemical structure of tangeretin is shown in Figure 1.

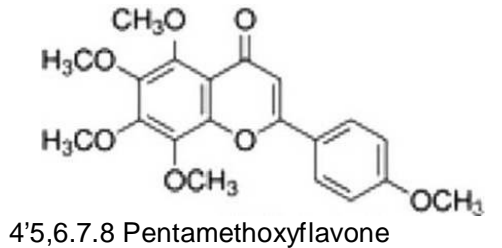

\section{EXPERIMENTAL}

\section{Animals}

In this study, 6-8 week-old male BALB/c mice were used. The experimental animals were housed in cages in a well-ventilated room at with average temperature of $23 \pm 2{ }^{\circ} \mathrm{C}$, and $61 \pm 4 \%$ moisture. The mice were given normal laboratory feed and water ad libitum, and were assigned to four different groups. Group I mice were injected with saline (intra peritoneal (i.p.) route) and served as normal control group, and group 2 (OVA) group was treated with OVA (i.p.), and served as bronchial airway asthma control group. Mice in group 3 were treated with OVA (i.p.) and $50 \mathrm{mg} / \mathrm{kg}$ tangeretin, while mice in group 4 received OVA (i.p.) and $100 \mathrm{mg} / \mathrm{kg}$ tangeretin. The study was approved by the Institutional Ethical Committee (approval no. 2017/2033). It was carried out in accordance with Good Clinical Practice and the Declaration of Helsinki Guidelines and all applicable regulatory requirements [7]. A schematic diagram of the study is shown in Figure 2.

\section{Chemicals and reagents}

In this study, the following chemicals and reagents were commercially obtained: OVA and $100 \%$ pure, endotoxin-free tangeretin (Simcere Doyea Pharmaceutical Co., China); bovine serum albumin (BSA, Atlanta Biologicals, Lawrenceville, GA, USA)); pancuronium bromide (Xi'an Miracle Biotechnology Co., Ltd.); antidinitrophenol (anti-DNP) and IgE mab (Atlanta Biologicals, Lawrenceville, USA); peroxidaselabeled anti-mouse IgE and goat IgG polyclonal antibody (Atlanta Biologicals (Lawrenceville,

Figure 1: Structure of tangretin

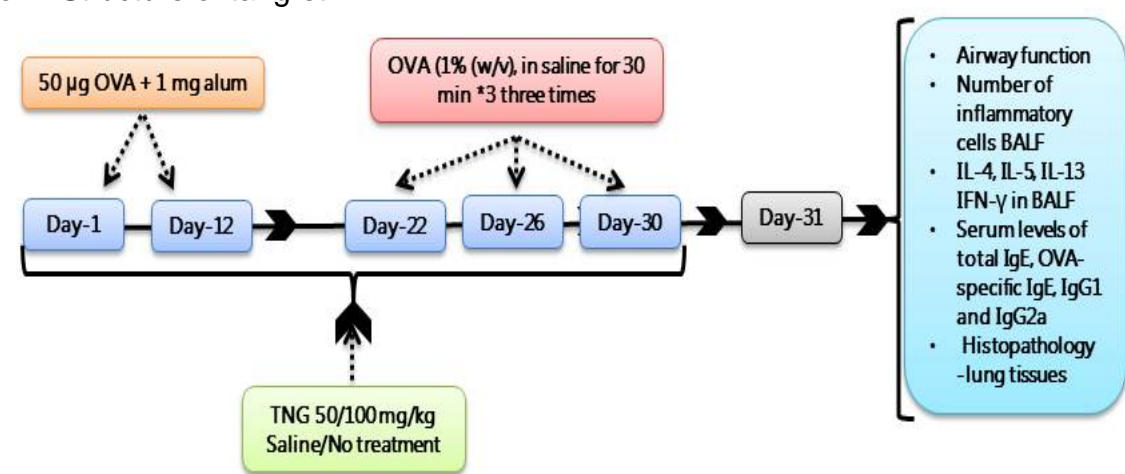

Figure 2: Schematic diagram of the study. Animals were actively sensitized by intraperitoneal injections of $50 \mu \mathrm{g}$ OVA with $1 \mathrm{mg}$ alum on days 1 and 12 . On $22^{\text {nd }}, 26^{\text {th }}$ and $30^{\text {th }}$ days, they were exposed to OVA (1\% (w/v) in sterile physiological saline) for $30 \mathrm{~min}$, each day. The negative control group mice were exposed to saline in a similar manner. Twenty-four hours after the final antigen challenge (on $31^{\text {st }}$ day), bronchial responsiveness to Ach was measured; BALF was collected, and lung sections were removed for histopathology. (Tangeritin was administered orally from day 1 to day 30 . On the day of sensitization and challenge, tangeritin was given 30 min before the treatment) 
USA); rat anti-mouse IgE mab (Santa Cruz, USA); goat anti-mouse IgG1 polyclonal antibody (Santa Cruz, USA); rat anti-mouse IgG2a mab (Invitrogen, Carlsbad, CA, USA); and peroxidase-conjugated streptavidin (Santa Cruz, USA).

\section{Sensitization and challenge}

The experimentations in this study were performed according to the procedures described by Balaha et al [8]. The experimental animals were sensitized by administering $50 \mu \mathrm{g}$ OVA (intraperitoneally) and $1 \mathrm{mg}$ of alum on day 1 and day 12. Furthermore, on days 22,24 and 30 , the animals were injected with $1 \% \mathrm{w} / \mathrm{v}$ solution of OVA in sterilized saline, 3 times each day. Mice in the normal control group were administered saline in the same manner. On day 31, after the last antigenic injection, the sensitivity of the respiratory mucous muscle to acetylcholine (Ach) was measured. Bronchial-alveolar lavage fluid (BALF) and lungs were collected for histopathological studies. Tangeretin was injected for 30 days (from day 1 to day 30 ). On the sensitization day, tangeretin was administered 30min prior to treatment (Figure 2).

\section{Measurement of airway function}

Bronchoconstriction was measured in accordance with the procedure of Balaha et al [8]. The experimental animals were anesthesized by intraperitoneal administration of sodium pentobarbitone $(60 \mathrm{mg} / \mathrm{kg})$, and Ach was administered through jugular vein cannulation. Furthermore, intravenous pancronium bromide $(0.1 \mathrm{mg} / \mathrm{kg})$ was injected to suppress inhalation, and the mice were allowed ventilation from oxygen-filled air at 120 beats/min, with beat size of $0.3 \mathrm{ml} / \mathrm{mouse}$. Respiratory constriction was tested by employing respiratory spasm transducer coupled to tracheal cannula. To determine respiratory tract sensitivity towards Ach, anomalies in bronchial excess volume were determined by employing ascending doses of Ach. Excess respiratory airflow exhibited by Ach was demonstrated as percentage of the maximal excess flow volume (100 \%) attained by fastening the respiratory tract cannula. The area under curve was measured from a doseresponse curve of Ach (range: 30.25 to 2,000 $\mu \mathrm{g} / \mathrm{kg}$ ). Each dose was transformed logarithmically, and the area under curve was measured and depicted as arbitrary units.

\section{Tests on BALF}

The accumulation of inflammation mediators in BALF was tested to determine respiratory tract inflammation. The experiments were performed according to the method of Balaha et al. [8]. Twenty-four hours after the terminal inhalational dose of the antigenic agent, the experimental animals were sacrificed under intraperitoneal sodium pentobarbitone $(100 \mathrm{mg} / \mathrm{kg})$ anaesthesia. The left bronchial tissue was knotted for histopathological studies, and the right airway tract was splashed four times with $0.5 \mathrm{ml}$ of phosphate buffered saline (PBS). The BALF from each mouse was collected in a plastic tube, chilled in icepack, and centrifuged at $150 \times \mathrm{g}$ for 10 min at $4{ }^{\circ} \mathrm{C}$. The resultant cell capsules were suspended in an equivalent volume of buffer (1 $\mathrm{mL}$ ). One part of the cell suspension was then suspended in Türk solution, and the nucleated cells were measured in a Bürker cubicle. A differentiating count was done on a cover slip smear made using a cyto-centrifuge, and then marked with Diff-Quick solvent. According to standard diagnostic selection, 300 cells were measured at an amplification of $\times 500$.

\section{Determination of cytokine concentrations in BALF}

The cytokine content of BALF suspension was analysed utilizing Biovision enzyme-linked immunosorbent assay (ELISA) kits for interleukin-4 (IL-4), interferon- $y$, interleukin-5 (IL5) and interleukin-13 (IL-13).

\section{Assay of serum immunoglobulin concentrations}

(Ig)

After administering the terminal dose on day 30 , sera samples were subjected to cryocentrifugation at $-30{ }^{\circ} \mathrm{C}$, and the resultant supernatants were used for further analysis. Total IgE, ovalbumin-specific IgE, ovalbuminspecific IgG1 and ovalbumin-specific IgG2a in the serum were determined by ELISA in line with the method of Balaha et al [8]. Total serum IgE was calculated by coating flat-bottomed microtiter plates with rat anti-mouse IgE mab (5 $\mu \mathrm{g} / \mathrm{mL}$ ). After blocking with $1 \%$ Block-Ace, the reference and serum dilutions were left to stand for one hour and then treated with peroxidaselabeled anti-mouse immunoglobulin E goat IgG polyclonal antibody. Diluted anti-DNP lgE mab was used as a reference.

Serum ovalbumin-specific IgE was determined by coating the microtiter plates with rat antimouse IgE antibody mab $(5 \mu \mathrm{g} / \mathrm{mL})$. Blocking was done with $1 \% \mathrm{BSA}$, and serum dilutions were left to stand for about one-hour. Serum ovalbumin-specific IgG1 was assayed by coating the microtiter plates with goat anti-mouse IgG1 polyclonal antibody $(2 \mu \mathrm{g} / \mathrm{mL})$. On coating with 1 
$\%$ BSA, serum dilutions were kept for $1 \mathrm{~h}$ followed by treatment with biotinylated-ovalbumin and peroxidase-conjugated streptavidin. Serum ovalbumin-specific immunoglobulin G2a was determined by layering the microtiter plates with ovalbumin solvent $(20 \mu \mathrm{g} / \mathrm{mL})$. Similarly, serum dilutions were kept for $1 \mathrm{~h}$ followed by treatment with peroxidase-conjugated monoclonal rat antimouse IgG2a antibody. Sequentially diluted monoclonal anti-OVA IgE, IgG1, and IgG2a were employed as reference standards. Absorbance was measured in a programmed ELISA detector at $492 \mathrm{~nm}$. The limit of detection was $1 \mathrm{ng} / \mathrm{mL}$ for aggregate $\lg \mathrm{E}$, anti-ovalbumin $\mathrm{IgE}$, and antiovalbumin IgG1. For anti-ovalbumin IgG2a, the limit of detection was $3 \mathrm{ng} / \mathrm{mL}$.

\section{Histopathology}

The left-side lung tissue sections of the animals were separated and fixed in newly-prepared 10 $\%$ formalin for about $24 \mathrm{~h}$. The fixed tissues were thereafter embedded in paraffin, and $5 \mu \mathrm{m}$ sections were cut and stained with Hematoxylin and Eosin ( $\mathrm{H} \quad$ \& $E)$ for histopathological examinations.

\section{Statistical analysis}

Data are expressed as mean \pm SEM, and were analysed by SPSS Statistics. Correlations were determined by one-way analysis of variance (ANOVA), followed by Tukey's test where appropriate. $P \leq 0.05$ was considered as indicative of statistical significance.
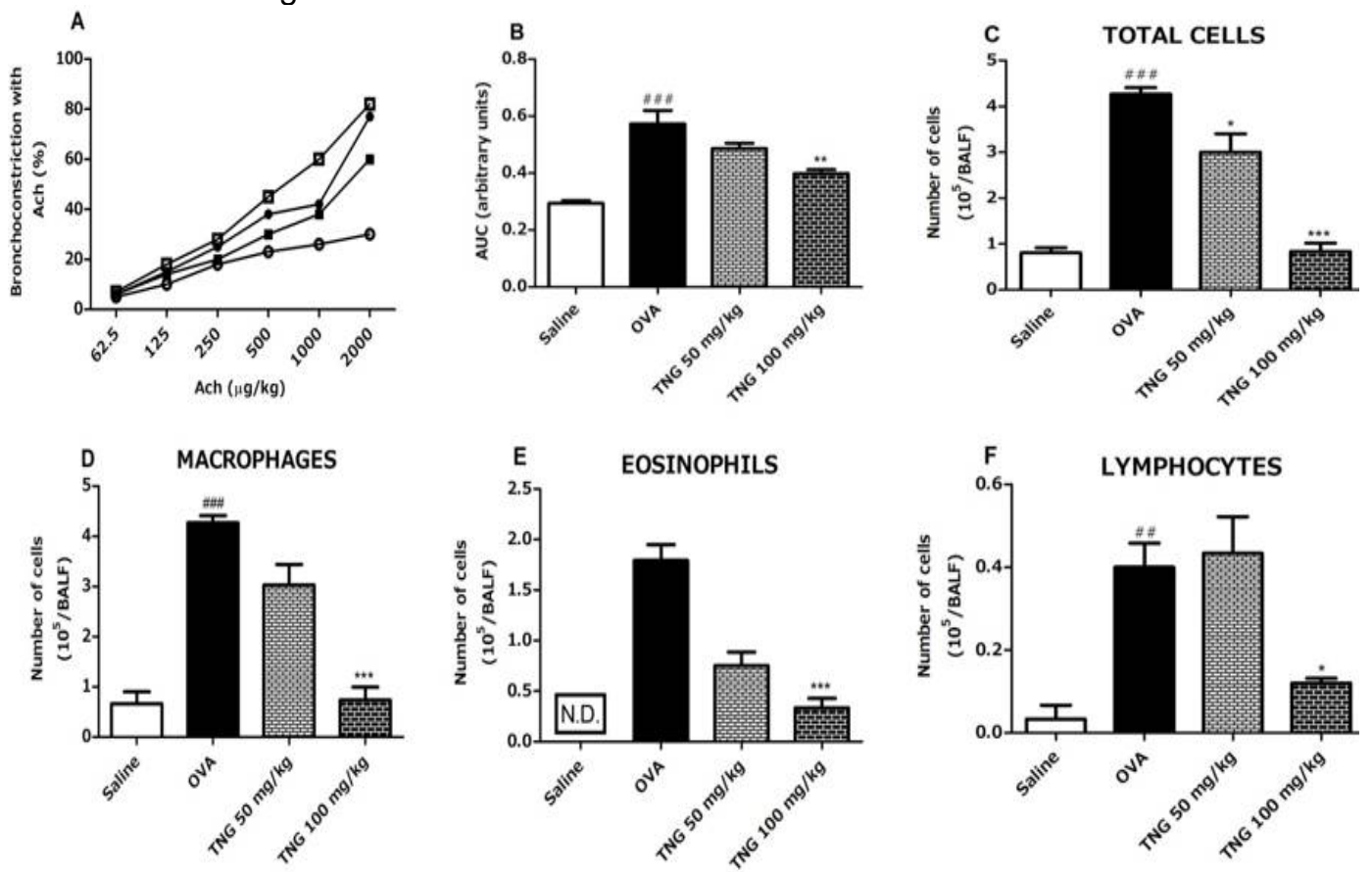

Figure 3: Effect of tangeritin on increased airway responsiveness to Ach and inflammatory infiltrates in BALF in OVA-induced bronchial asthma of BALB/c mice 

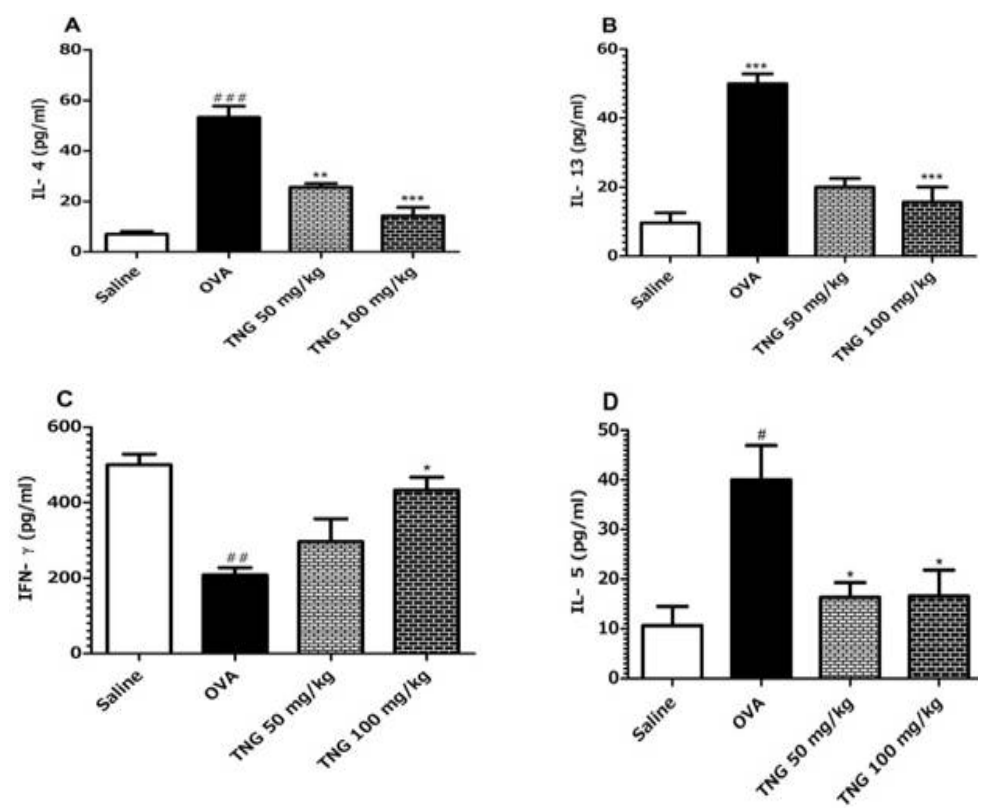

Figure 4: Effect of tangeritin on increased cytokine levels in BALF in OVA-induced bronchial asthma of BALB/C mice 24-h after the final antigen challenge. Values represent mean \pm SEM for six animals in each group. $A=I L-4$, $B=I L-13, C=I F N-\gamma, D=I L-5$. Saline = saline exposed group; OVA = non-treated bronchial asthma group; TNG $50 \mathrm{mg} / \mathrm{kg}=$ bronchial asthma group treated with $50 \mathrm{mg} / \mathrm{kg}$ tangeritin. ${ }^{\#} P<0.05,{ }^{\# \#} p<0.01,{ }^{\# \#} p<.001$ (vs. saline group); ${ }^{*} p<0.05,{ }^{* \star} p<0.01,{ }^{* * *} p<.001$ (vs. OVA group)

\section{Effect of tangeretin on serum immune- glbulins}

Parenteral and local ovalbumin insult markedly raised the levels of serum total IgE, ovalbuminspecific $\lg \mathrm{E}, \lg G 1$ and $\lg \mathrm{G} 2 a$. Pre-treatment with tangeretin significantly reversed the increases in concentrations of total $\mathrm{lgE}$, ovalbumin-specific $\lg \mathrm{E}$ and IgG1 in a dose-dependent fashion. On the other hand, tangeretin significantly increased the levels of ovalbumin-specific IgG2a at a dose of $100 \mathrm{mg} / \mathrm{kg}$ (Figure 5).

\section{Effect of tangeretin on histopathological abnormalities}

Figure 6 shows representative photomicrographs of lung tissue sections of the experimental animal groups (H\&E). Ovalbumin (OVA) injection resulted in perivascular and peribronchial cellular infiltration, raised condensation of respiratory tracheal muscle, epithelial hyperplasia, and flaked epithelial lining. However, injection of tangeretin at a dose of $100 \mathrm{mg} / \mathrm{kg}$ substantially ameliorated the histopathological anomalies caused by OVA (Figure 6).

\section{DISCUSSION}

In this study, the immunomodulatory and antiinflammatory activities of tangeretin were determined in a mouse model of bronchial asthma in relation to bronchial function, antigenprompted, inflammation-mediated fluid secretion in the bronchial airways, local cytokine (Th1/Th2) secretion, serum immunoglobulin contents, and lung histopathology. Several animal models have been developed for studying new pharmacological interventions for allergic asthma. In the present study, experimental mice model was chosen. This model can simulate all the characteristic traits of bronchial inflammation in humans [9].

In the present investigation, tangeretin administration in mice challenged with OVA substantially improved airway hyperresponsiveness, decreased total counts of eosinophils, macrophages and leukocytes, and reduced the concentrations of proinflammatory cytokines in BALF. Serum concentrations of OVA-specific $\lg E$, total $\lg E$ and $\lg G 1$ were also significantly reduced by tangeretin.

Generally, Th-2 type 2 cytokines (II-4, II-5 and II13) act as crucial factors in the precipitation of bronchial asthma in humans [10]. Among these cytokines, IL-4 stimulates the separation and propagation of Th2-type T-cells, and promotes the secretion of $\lg G 1$ and $\lg E$ by B-cells. Stalling of IL-4 by monoclonal antibodies (MABs) reduces $\lg \mathrm{E}$ concentration and bronchial eosinophilia in hypersensitive mouse [11]. Interleukin-5 can function as a vital contributor in the segregation, maturation and survival of eosinophils, which accounts for its rise in bronchial constriction. Previous studies have demonstrated that eosinophilia-induced inflammation would not 

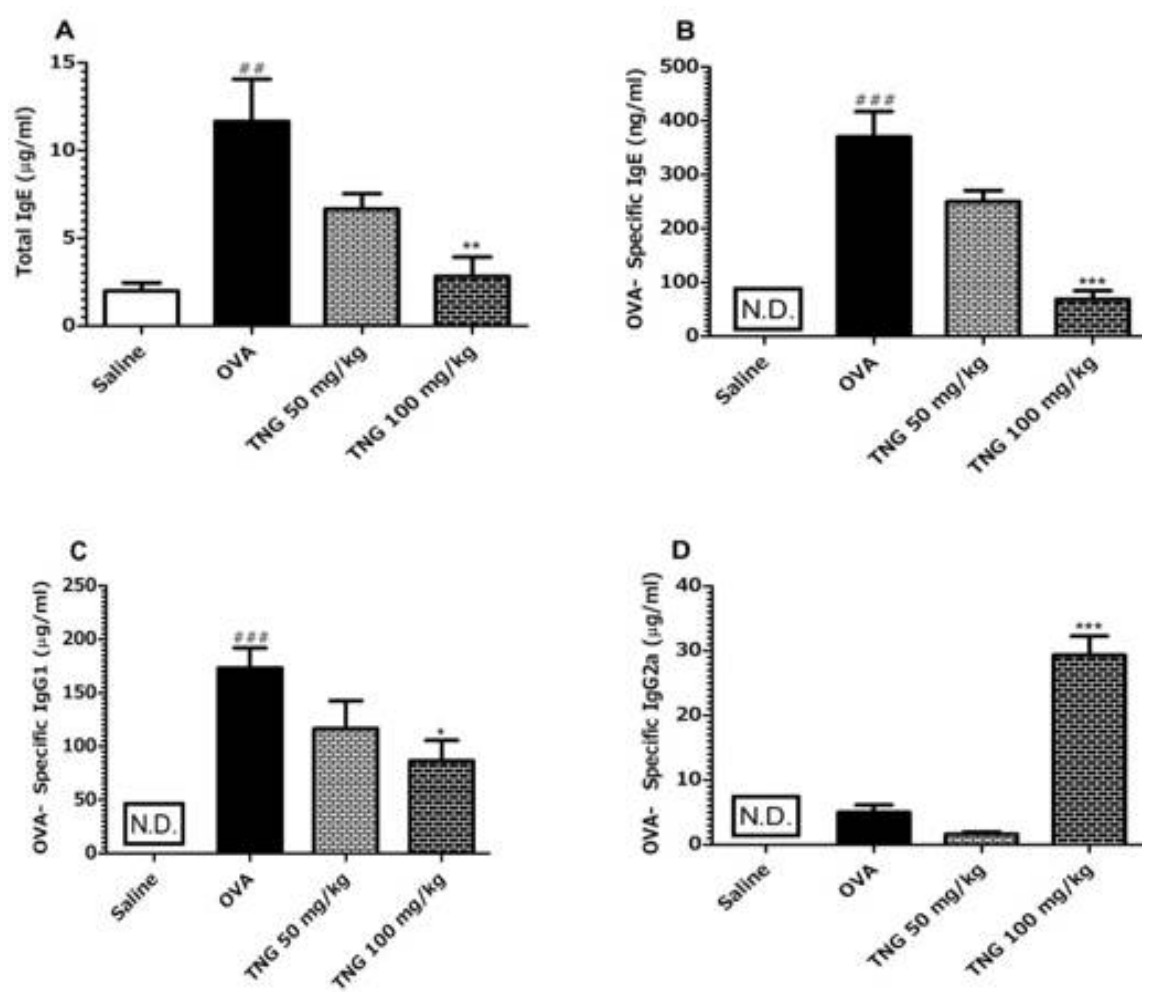

Figure 5: Effect of tangeritin on increased serum immunoglobulin levels in OVA-induced bronchial asthma of $B A L B / c$ mice after the final allergen challenge. Values represent mean \pm S.E.M. for six animals in each group. A $=$ Total $\lg \mathrm{E}, \mathrm{B}=$ OVA-specific $\lg \mathrm{E}, \mathrm{C}=$ Ova-specific IgG1, D = OVA-specific IgG2a, Saline = saline-exposed group; OVA = non-treated bronchial asthma group; TNG $50 \mathrm{mg} / \mathrm{kg}=$ bronchial asthma group treated with $50 \mathrm{mg} / \mathrm{kg}$ tangeritin; N.D. = not detected. ${ }^{\# \#} p<0.01,{ }^{\# \#} p<0.001$ (vs. Saline group); $p<0.05, \quad p<0.01,{ }^{* * *} p<0.001$ (vs. OVA group)

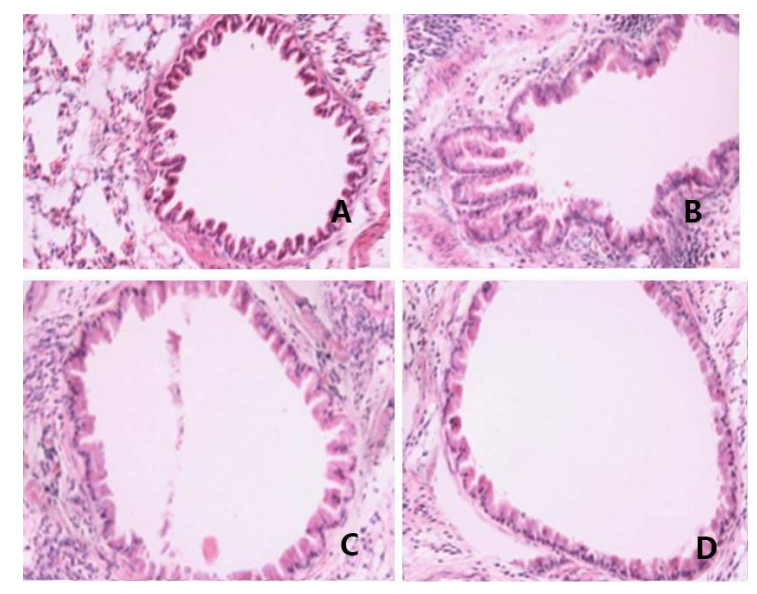

Figure 6: Effect of TNG on histopathological alterations of lung tissues in OVA-induced bronchial asthma in BALB/c mice. A: Saline exposed group, B:Non-treated bronchial asthma group, C: Bronchial asthma group treated with TNG $50 \mathrm{mg} / \mathrm{kg}$, D: Bronchial asthma group treated with TNG $100 \mathrm{mg} / \mathrm{kg}$ (H\&E staining, $\times 200$ )

develop without the activity of interleukin-5 or without its function in the trachea of OVA-treated animals [12].

Interleukin-13 is implicated in airway hyperresponsiveness. It induces $\lg E$ isotype switchover in B-cells and mucus secretion in the bronchial airways. It has been shown that IL-13 knockout mouse failed to develop airway hyperresponsiveness from allergen exposure even after developing severe bronchial inflammatory reaction [13]. In contrast to the Th2 cytokines, inteferon-y secreted by Th1 cells can increase secretion of $\lg \mathrm{G} 2 \mathrm{a}, \lg \mathrm{E}$ and antigen-provoked eosinophils [14]. Consequently, replenishment of local cytokine homeostasis (balance in Th1/Th2 ratio) is an appropriate strategy for discovering new anti-asthma drugs.

In this study, tangeretin $\left(4^{\prime}, 5,6,7,8\right.$ pentamethoxyflavone) was tested as an intervention for asthma. Studies have revealed that tangeritin possesses potential antiinflammatory, anti-proliferative and chemopreventive properties [15]. In addition, previous studies have also showed that tangeretin reduced inflammation-related cyclooxygenase (COX-2) activity in lung epithelial carcinoma cells [15], and provoked G1 cell cycle arrest in breast and colon carcinomas [16]. In view of these beneficial effects of tangeretin, its anti-asthma activity was investigated in the .present study. The results showed that exposure of OVA-treated mice to tangeretin inhibited Th2 cytokine secretions (IL-4, IL-5 and IL-13) in a dose-dependant fashion, and 
increased the secretion of Th1 cytokine (interferon- $y$ ) in BALF. Increased production of local cytokines (Th1/Th2) is consistent with airway hyper-responsiveness, lowered bronchial inflammation and cellular infiltration, and decreased total $\lg \mathrm{E}$, ovalbumin-specific $\lg \mathrm{E}$ and raised IgG2a [17]. The effect exhibited by tangeretin could be ascribed to its antioxidant and anti-inflammatory properties which have been reported in previous studies [15].

Except for IFN-y production, all the cytokines were affected by tangeretin. This is in agreement with previous reports [8]. In this study, the animal group sensitized with OVA had lower levels of IFN-y when compared to the saline group and drug-treated group. In contrast, a previous study reported that the concentration of IFN- $\gamma$ in the blood of sensitized and challenged guinea pigs was comparatively higher than that of normal controls [18]. This difference in IFN- $\gamma$ secretion could be due to difference in the experimental animal models used. There exist a diversity in immunization procedure, antigen used, and frequency and level of stimulating antigen in the various animal models of asthma. These differences could influence asthma-like symptoms [18]. Indeed, these conflicting observations were also witnessed in the current study. Nevertheless, since asthma produces diverse manifestations in different models, one should take note of the salient, characteristic features in a particular animal model such that each critical parameter is represented in that experimental model.

The animal model employed in this study is known to exhibit all the characteristic traits of allergic bronchial swelling in human beings. However, the model limits one to examination of bronchial remodelling, particularly sub-epithelial and respiratory airway hypertrophy and hyperplasia. Moreover, the OVA used for inducing asthma might not be an appropriate antigenic agent in humans. Hence, further studies are required on the possible ameliorating activity of tangeretin using a chronic experimental animal model [17].

\section{CONCLUSION}

The findings of this study demonstrate the antiasthmatic effect of tangeretin against OVAprovoked respiratory airway allergic asthma in mice. The ameliorating effect of tangeretin may be mainly due to its effect on cytokine secretion. These results suggest that tangeretin may be a potential agent for treating bronchial airway allergic asthma.

\section{DECLARATIONS}

\section{Acknowledgement}

The authors would like to thank Zhangqiu Hospital of Traditional Chinese Medicine for financial support. No grant was received from any other organization.

\section{Conflict of interest}

The authors declare that no conflict of interest is associated with this work

\section{Contribution of authors}

We declare that this work was done by the authors named in this article and all liabilities pertaining to claims relating to the content of this article will be borne by the authors. Liang-Mei Li conceived and designed the study. Wei Liu collected and analysed the data. Liang-Mei Li and Wei Liu wrote the manuscript. The manuscript was read and approved for publication by all the authors.

\section{REFERENCES}

1. Masoli $M$, Fabian $D$, Holt $S$, Beasley $R$, Global Initiative for Asthma (GINA) Program. The global burden of asthma: executive summary of the GINA Dissemination Committee report. Allergy 2004; 59: 469-478.

2. Kim DY. and Yang WM. Panax ginseng ameliorates airway inflammation in an ovalbumin-sensitized mouse allergic asthma model. J Ethnopharmacol, 2011. 136: 230-235.

3. $X u G H$, Chen JC, Liu $D H$, Zhang $Y H$, Jiang $P$, Ye XQ. Minerals, phenolic compounds, and antioxidant capacity of citrus peel extract by hot water. J Food Sci 2008; 73: C11-C18.

4. Yoon JH, Lim TG, Lee KM, Jeon AJ, Kim SY, Lee KW. Tangeretin reduces ultraviolet $B$ (UVB)-induced cyclooxygenase-2 expression in mouse epidermal cells by blocking mitogen-activated protein kinase (MAPK) activation and reactive oxygen species (ROS) generation. J Agric Food Chem 2011; 59: 222-228.

5. Sundaram $R$, Shanthi $P$, Sachdanandam $P$. Effect of tangeretin, a polymethoxylated flavone on glucose metabolism in streptozotocin-induced diabetic rats. Phytomedicine 2014; 21: 793-739.

6. Cheng Z, Surichan S, Ruparelia K, Arroo R, Boarder MR. Tangeretin and its metabolite 4'-hydroxytetramethoxyflavone attenuate EGF-stimulated cell cycle progression in hepatocytes; role of inhibition at the level of mTOR/p70S6K. Br J Pharmacol 2011; 162: 17811791.

7. WHO. Declaration of Helsinki. Ethical Principles for Medical Research Involving Human Subjects. 2000.

Trop J Pharm Res, February 2018; 17(2): 259 
Available at: http://www.who.int/bulletin/archives/79\% 284\%29373.pdf accessed on 07 Dec 2017.

8. Balaha MF, Tanaka H, Yamashita H, Abdel Rahman MN, Inagaki N. Oral Nigella sativa oil ameliorates ovalbumininduced bronchial asthma in mice. Int Immunopharmacol 2012; 14: 224-231.

9. Ishizaki M, Tanaka H, Kajiwara D, Toyohara T, Wakahara $K$, Inagaki $N$, Nagai $H$. Nafamostat mesilate, a potent serine protease inhibitor, inhibits airway eosinophilic inflammation and airway epithelial remodeling in a murine model of allergic asthma. J Pharmacol Sci 2008; 108: 355-363.

10. Cohn L, Elias JA, Chupp GL. Asthma: mechanisms of disease persistence and progression. Annu Rev Immunol 2004; 22: 789-815.

11. Blaeser F, Bryce PJ, Ho N, Raman V, Dedeoglu F, Donaldson DD, Geha RS, Oettgen HC, Chatila TA. Targeted Inactivation of the IL-4 Receptor a Chain I4R Motif Promotes Allergic Airway Inflammation. J Exp Med 2003; 198: 1189-200.

12. Tanaka H, Kawada N, Yamada T, Kawada K, Takatsu K, Nagai $H$. Allergen-induced airway inflammation and bronchial responsiveness in interleukin-5 receptor alpha chain-deficient mice. Clin Exp Allergy 2000; 30: 874881.

13. Grünig G, Warnock $M$, Wakil AE, Venkayya $R$, Brombacher F, Rennick DM, Sheppard D, Mohrs M,
Donaldson DD, Locksley RM, Corry DB. Requirement for IL-13 independently of IL-4 in experimental asthma. Science 1998; 282: 2261-2263.

14. Iwamoto I, Nakajima $H$, Endo $H$, Yoshida S. Interferon gamma regulates antigen-induced eosinophil recruitment into the mouse airways by inhibiting the infiltration of CD4+ T cells. J Exp Med 1993; 177: 573576.

15. Chen KH1, Weng MS, Lin JK. Tangeretin suppresses IL1beta-induced cyclooxygenase (COX)-2 expression through inhibition of p38 MAPK, JNK, and AKT activation in human lung carcinoma cells. Biochem Pharmacol 2007; 73: 215-227.

16. Morley KL, Ferguson PJ, Koropatnick J. Tangeretin and nobiletin induce $\mathrm{G} 1$ cell cycle arrest but not apoptosis in human breast and colon cancer cells. Cancer Lett 2007; 251: 168-178.

17. Komai M, Tanaka $H$, Masuda $T$, Nagao K, Ishizaki M, Sawada $M$, Nagai $H$. Role of Th2 responses in the development of allergen-induced airway remodelling in a murine model of allergic asthma. Br J Pharmacol 2003; 138: 912-920.

18. Williams CM, Galli SJ. Mast cells can amplify airway reactivity and features of chronic inflammation in an asthma model in mice. J Exp Med 2000; 192: 455-462. 